\title{
The Effects of Age on Short-Term Memory Loss due to Proactive Interference
}

\author{
Alisha Berkauzer \\ University of South Florida
}

\author{
Advisors: \\ Arcadii Grinshpan, Mathematics and Statistics \\ Andrei Chugunov, Fortis College: Medical Sciences \\ Problem Suggested By: Andrei Chugunov
}

Follow this and additional works at: https://digitalcommons.usf.edu/ujmm

Part of the Mathematics Commons

UJMM is an open access journal, free to authors and readers, and relies on your support: Donate Now

\section{Recommended Citation}

Berkauzer, Alisha (2011) "The Effects of Age on Short-Term Memory Loss due to Proactive Interference," Undergraduate Journal of Mathematical Modeling: One + Two: Vol. 4: Iss. 1, Article 2.

DOI: http://dx.doi.org/10.5038/2326-3652.4.1.2

Available at: https://digitalcommons.usf.edu/ujmm/vol4/iss1/2 


\title{
The Effects of Age on Short-Term Memory Loss due to Proactive Interference
}

\author{
Abstract \\ This project focused on how proactive interference affects the short-term memory of people based on \\ their age. The goal was to find the prime age for learning information and storing it in one's memory. \\ Seven people from ages fifteen to forty were tested individually, using a set color pattern, in order to see \\ how well each individual could remember the different color patterns as difficulty of the pattern increased. \\ The obtained data was fitted by the polynomial regression. The "fitted" curve shows that as age \\ increases, the individual's performance in memorizing the more difficult patterns decreases. Also, the \\ peaked level of memory performance was found to be 24 for our experimental data.
}

\section{Keywords}

Proactive interference, Short Term Memory, Aging

Creative Commons License

(c) (i) ()

This work is licensed under a Creative Commons Attribution-Noncommercial-Share Alike 4.0 License. 


\section{TABLE OF CONTENTS}

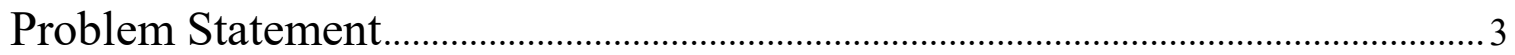

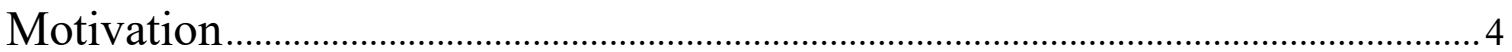

Mathematical Description and Solution Approach ...............................................

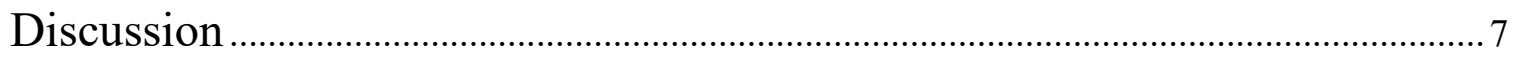

Conclusion and Recommendations....................................................................

Nomenclature

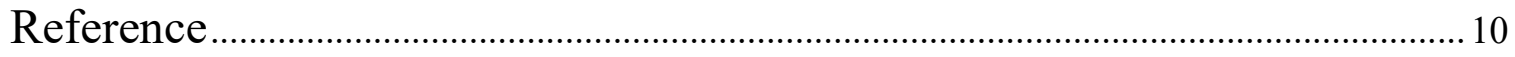




\section{PROBLEM STATEMENT}

The goal of this project is to determine the optimal age for retaining old information as new information is introduced creating proactive interference. Six people from ages fifteen to forty were tested individually using a set color pattern and each person was assigned a pattern difficulty level (PDL) ranging from one to nine.

The PDL represents the highest combination of colors the person could remember without any error when repeating them. From this information, the pattern difficulty level was plotted against the individual's age and fitted by polynomial regression. Based on our results, the peak age (optimal age) for remembering old information when new information is presented, is twenty four. Although the results were not a perfect-match with the other studies, which show that the peak age for memorization is twenty-two, this study is consistent with other studies by showing that as age increases, memory performance decreases. With some improvements, it is believed that this study would be in compliance with other well-known studies such as those conducted by Salthouse Cognitive Aging Lab (Salthouse 2009) at the University of Virginia.

\section{MOTIVATION}

Quantifying the effects of age on memory is significant to many areas of studies today, especially to those who are in the medical field, cognitive studies, and neurological studies. As technology increases, the amount of daily information a person encounters increases as well. People are constantly being expected to remember old information, as well as new information presented to them in short periods of time. Students especially are subject to proactive interference throughout their studies. 
Proactive memory studies can be used to monitor the changes in a healthy brain or assist in determining the pathology of various neurological disorders such as dementia. Although this is a basic study of short-term memory loss, it can be revised to test other forms of memory loss.

\section{MATHEMATICAL DESCRIPTION AND SOLUTION APPROACH}

This problem requires the testing of people from different age groups. We obtained our data by testing seven people with different ages. As can be seen by Figure 1, the PDL scores tended to decrease as age increased. This suggests that people of greater age are will have greater difficulty with proactive interference color patterns.

We begin by modeling our data using Excel and polynomial regression. Polynomial regression establishes a relationship between an independent variable $x$ and a dependent variable $f(x)$ in the form of an $n^{\text {th }}$ order polynomial,

$$
f(x)=a_{0}+a_{1} x+a_{2} x^{2}+a_{3} x^{3}+\cdots+a_{n} x^{n}+\varepsilon
$$

The coefficients are estimated using the least square method, a numerical method which minimizes the sum of the square errors between the actual data points and the fitted line.

As can be seen in Figure 1, the experimental data is nicely fit by the $2^{\text {nd }}$ order (quadratic) polynomial,

$$
f(x)=-0.0125 x^{2}+0.5921 x+1.2152
$$




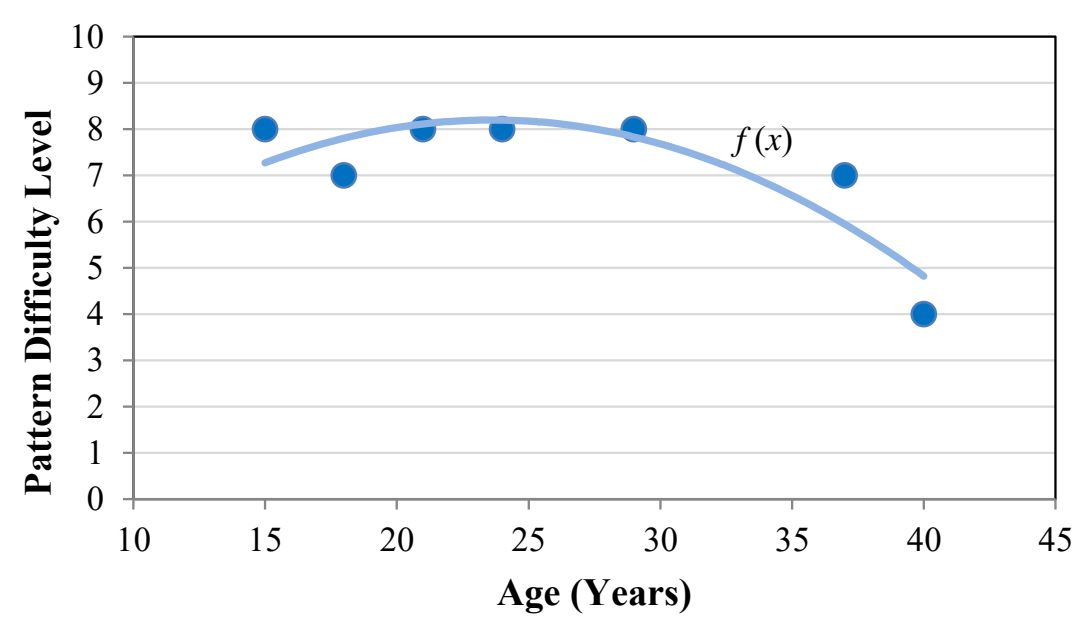

\begin{tabular}{|cc|}
\hline Age & $\begin{array}{c}\text { Pattern } \\
\text { Difficulty Level }\end{array}$ \\
\hline 15 & 8 \\
\hline 18 & 7 \\
\hline 21 & 8 \\
\hline 24 & 8 \\
\hline 29 & 8 \\
\hline 37 & 7 \\
\hline 40 & 4 \\
\hline
\end{tabular}

Figure 1: Number of colors remembered in the pattern vs. each participant's age.

The quadratic regression curve (2) suggests that, after some point, short-term memory regresses as age increases. We find this point by locating the age where the PDL is maximized, i.e., we find the first derivative of the fitted line (2) and setting it equal to zero. The maximum or peak age of short-term memorization is reached when

$$
f^{\prime}(x)=-0.025 x+0.5921=0
$$

This occurs at $x=23.684$. Thus our experimental data shows that the approximate peak age for retaining short-term information is 24 .

Although the maximum of our regression function was easy to find explicitly, there is a possibility that the fitted polynomial regression curve is a higher degree polynomial. For any polynomial with degree greater than or equal to 4 , the resulting derivative becomes a polynomial of degree 3 or greater. For such cases, solving for the zeros of the derivative requires additional computation. 


\section{DISCUSSION}

In this experiment, seven participants from various age groups ( $15-40$ years old $)$ were given a set of four colored cards: blue, red, orange, and yellow. At the beginning of each round, a participant was shown a colored card and asked to recall the full sequence of colors up to the current round.

Four out of the seven participants completed round 8 without a mistake. As seen in Table 1, all members of the age group $15-29$ completed round 8 with the exception of the 18 year old who completed round 7 . The 40 year old participant only completed round 4 , which is a very significant difference compared with the others tested.

\begin{tabular}{|c|c|}
\hline Round & Color \\
\hline 1. & Blue \\
\hline 2. & Red \\
\hline 3. & Blue \\
\hline 4. & Orange \\
\hline 5. & Yellow \\
\hline 6. & Yellow \\
\hline 7. & Red \\
\hline 8. & Orange \\
\hline 9. & Blue \\
\hline 10. & Yellow \\
\hline
\end{tabular}

Table 2: Sequence of colors

This suggests that young adults and adolescents may each participant was asked to remember.

have better short-term memorization skills when it comes to storing old information as new information is added (proactive interference). The best fit curve (2) for our data, indicates that the pattern difficulty levels decrease with age. These results comply with a medical study done by Salthouse that found that the peak age for storing information is twenty-two (Salthouse 2009).

\section{CONCLUSION AND RECOMMENDATIONS}

By using calculus with the assistance of Excel, the peak age for storing information was determined to be 24 years old. This is consistent with the 2000 participant study where the peak age was found to be 22 (Salthouse 2009). In fact, there is only a small percent error of $9 \%$ 
between these two ages. This shows that a large-scale study is not always needed to find precise results.

It should be noted that the Salthouse study did not find the decrease in performance to be quadratic, but the general trends of the two studies are in compliance with one another. Since this study was able to confirm the findings of a much larger study, we have shown that these are precise results.

One recommendation is to adapt the test to find more than the peak age for storing information. It would be useful to see what type of information is easier to store. For some, the visual aspect of this study may have benefited them more, but others may be able to remember a series of sounds more easily. Most studies ignore this and focus on the visual aspects of retaining information. For further studying it may be beneficial to have one test focus on visual memory while another tests auditory memory.

Since most studies show that the peak age for retaining information is in the early twenties, another study could focus on a larger scale of people from age 20 to 29 to better determine the peak age rather than sampling older ages which have been found to be beyond peak. By focusing on this interval it may be easier to pinpoint an exact age at which short-term memory is best retained. 


\section{NOMENCLATURE}

\begin{tabular}{|cll|}
\hline Symbol & Definition & Units \\
\hline$x$ & Age & Years \\
\hline$f(x)$ & Pattern difficulty level & Color Combinations \\
\hline
\end{tabular}

\section{REFERENCE}

Salthouse, Timothy A. "When does age-related cognitive decline begin?" Neurobiology of Aging. 30 (4) (2009). pp. 507-514. 